\title{
Study of a Clean Microgrid for the Japanese Antarctica Showa Base
}

\author{
$F$ Shoki $^{1, *}, S$ Obara $^{1}$ \\ ${ }^{1}$ Kitami Institute of Technology, 165 Koen -cho, Kitami, Hokkaido 090-8507, Japan
}

\begin{abstract}
The Antarctica Showa Base has been powered primarily by diesel power generation. However, heavy oil fossil fuel is used for power generation by diesel generators. The Showa base is located in Antarctica, so there is heat demand throughout the year. Therefore, the capacity of transportation of fuel and emissions of carbon dioxide has become an issue. For these reasons, the construction of clean energy systems using renewable energy in order to locally produce energy for local consumption is being planned. In this study, we will design a microgrid based on the introduction of renewable energy (photovoltaics generation and wind power generators) and solid oxide fuel cell (SOFC), which does not emit carbon dioxide during power generation and can use heat cascades. However, there is a risk of a power failure because the power quality decreases with the introduction of renewable energy. In this paper, we clarified the introduction rate of renewable energy with the lowest frequency fluctuation and clarified the introduction limit of renewable energy in summer and winter.
\end{abstract}

\section{Introduction}

Currently, diesel power generation is the majority of the power supply at the Antarctica Showa Base of Japan [1]. However, heavy oil fossil fuel is used for power generation by diesel generators. The cost of transportation of fuel and emissions of carbon dioxide has become an issue [2]. Securing locally produced energy for local consumption to reduce transportation costs and lowering the number of carbon emissions is required [3]. In this study, we examined the microgrid of renewable energy which was introduced at the Antarctica Showa Base. However, when the renewable energy ratio of the system is increased, the frequency fluctuations in the power grid is increased by the output fluctuation [4]. In this paper, we analyzed the frequency variation of the Antarctica Showa Base microgrid (SBMG). We clarified the smallest frequency variation proportion of the amount of Photovoltaics and wind power generation. The Showa base is located in Antarctica, so there is a great demand for heat in winter. Therefore, we investigated the limits of the introduction of renewable energy in summer and winter when a solid oxide fuel cell (SOFC) that does not release carbon dioxide during power generation and can use heat cascades was introduced.

\section{Proposed energy system}

A system configuration diagram for the proposed SBMG is shown in Figure. 1. The SBMG consists of three diesel engine generators installed in a power generation building, photovoltaics, and wind power generator [5]. In addition, connecting to a diesel generator compensates for the output fluctuation of renewable energy. The surplus electricity generated in summer and mid-term is used to produce hydrogen in the water electrolyzer. On the other hand, Showa Station, Antarctica, has a huge heat demand in winter. Heat is therefore supplied by engine waste heat, residential seawater heat pumps and storage tanks, and other building storage heaters. In summer and midterm, power is supplied by Photovoltaics and wind power. In winter, power is supplied by wind power and fuel cells because the sun is not rising all day long.

\section{Analysis model}

The power quality analysis model of SBMG prepared with MATLAB/Simulink R2017a is shown in Figure. 2. The swing equation of the generator shown in Equation (1) is modeled in the block diagram of the diesel generator. When the output renewable energy and load fluctuates, unbalanced mechanical and electrical torques and frequency variation occur. Frequency is controlled by the PI control of the control model parts. PI control is adjusting the throttle opening degree of the diesel engine in order to keep the frequency to $50 \mathrm{~Hz}$. Where $T_{m}[\mathrm{~N} \cdot \mathrm{m}]$ is the mechanical torque, $T_{e}$ $[\mathrm{N} \cdot \mathrm{m}]$ is the electrical torque, $\mathrm{J}\left[\mathrm{kg} \cdot \mathrm{m}^{2}\right]$ is the inertia constant, and $\omega[\mathrm{rad} / \mathrm{s}]$ is the angular rotation speed.

\footnotetext{
Corresponding author: m1852300170@std.kitami-it.ac.jp
} 


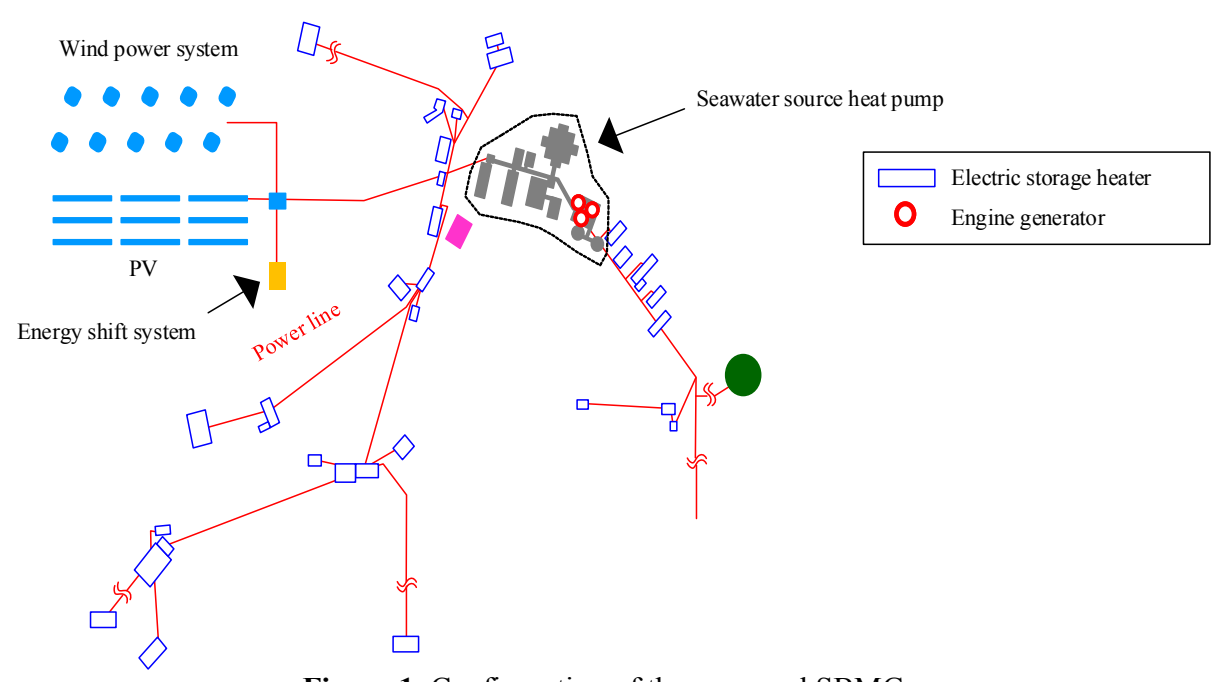

Figure 1. Configuration of the proposed SBMG.

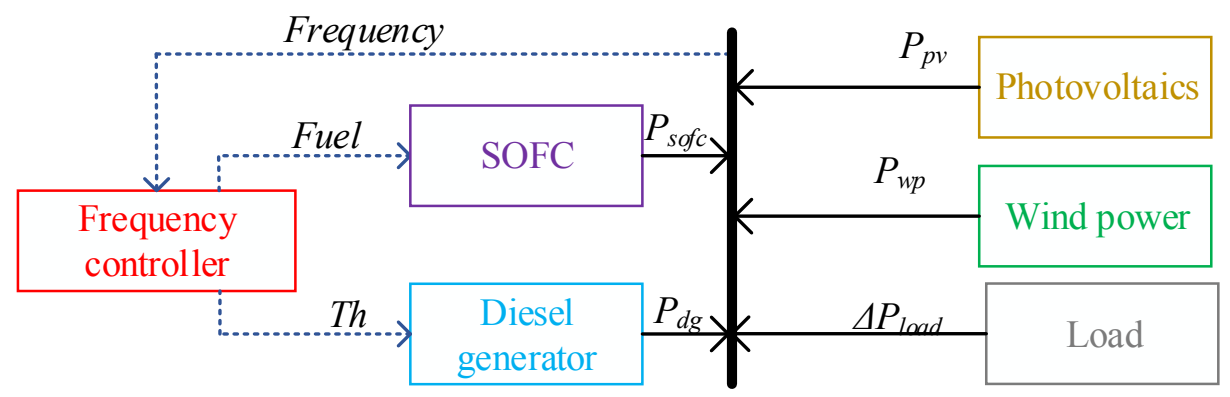

Figure 2. Analysis model.

$$
T_{m}-T_{e}=\mathrm{J} \frac{d \omega}{d t}
$$

\section{Analysis way}

4.1 Optimal introduction percentage Photovoltaics and wind power generation
The ratio of Photovoltaics and wind power generation is varied in a case shown in Table 1. Among them, it is revealed the smallest case of frequency variation. Here, the allowable amount of renewable energy of the maximum load is $10 \mathrm{~kW}$.

Table 1. Analysis case.

\begin{tabular}{|c|c|c|c|c|}
\hline \multirow{2}{*}{ Case } & \multicolumn{2}{|c|}{ Photovoltaics } & \multicolumn{2}{c|}{ Wind power } \\
\cline { 2 - 5 } & Percentage & Capacity & Percentage & Capacity \\
\cline { 2 - 5 } & {$[\%]$} & {$[\mathbf{k W}]$} & {$[\%]$} & {$[\mathbf{k W}]$} \\
\hline A & 100 & 10 & 0 & 0 \\
\hline B & 90 & 9 & 10 & 1 \\
\hline C & 80 & 8 & 20 & 2 \\
\hline D & 70 & 7 & 30 & 3 \\
\hline E & 60 & 6 & 40 & 4 \\
\hline F & 50 & 5 & 50 & 5 \\
\hline G & 40 & 4 & 60 & 6 \\
\hline H & 30 & 3 & 70 & 7 \\
\hline I & 20 & 2 & 80 & 8 \\
\hline J & 10 & 1 & 90 & 9 \\
\hline K & 0 & 0 & 100 & 10 \\
\hline
\end{tabular}




\subsection{Introduction limit of renewable energy in summer and winter}

The ratio of photovoltaic power generation to wind power generation introduced is the ratio obtained in the analysis of 3.1) above. The SOFC rated power is 100 $\mathrm{kW}$, the operating temperature is $1273 \mathrm{~K}$, and the power generation efficiency is 0.95 [6]. The output of renewable energy provides a step of changing from rated power to zero, and it is clarified whether the frequency fluctuation of the renewable energy transmission network is within the specified value of Hokkaido power in summer and winter is shown.

\section{Analysis condition}

In the Analysis, the sum of the load is $200 \mathrm{~kW}$. This load is the maximum load that is assumed in the SBMG. The output fluctuation of renewable energy used in the analysis is assumed to be the largest change. The change in the amount of solar radiation is a step change from the $1 \mathrm{~kW} / \mathrm{m}^{2}$ to $0 \mathrm{~kW} / \mathrm{m}^{2}$. The changes in wind speed are the step change from the rated wind speed to the cut-off wind speed. These two output fluctuations of the photovoltaics and wind generation occur at the same time, producing a step change from the rated output of the wind and photovoltaics to zero. This analysis is performed by MATLAB/ Simulink R2017a in $0.01 \mathrm{~s}$ of sampling time.

\section{Analysis result}

\subsection{Optimal introduction percentage of Photovoltaics and wind power generation}

Figure 3. is the maximum value of the frequency deviation of each case. From Figure. 3, it can be seen that frequency fluctuation in the system when it is introduced in combination with Photovoltaics and wind

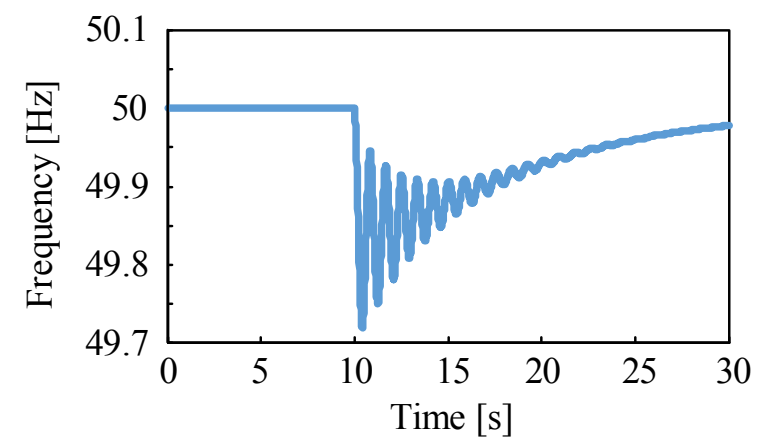

(a)Summer power is suppressed. This is because the Photovoltaics and wind power generation cancels the output fluctuation of each other. In addition, the maximum value of the frequency deviation of case $\mathrm{F}$ is small. Case F can afford the introduction of renewable energy because the largest frequency deviation is $0.188 \mathrm{~Hz}$.

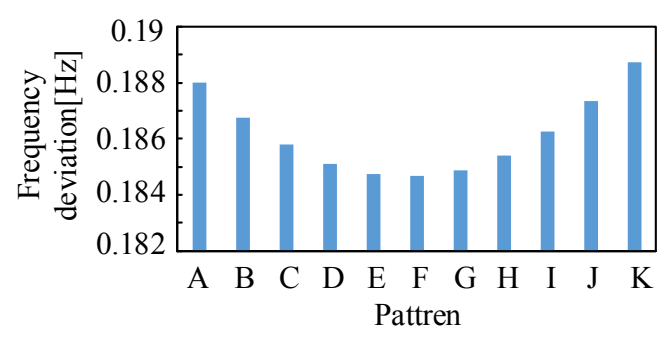

Figure 3. Frequency deviation of each case.

\subsection{Introduction limit amount of renewable energy in summer and winter}

The result of the frequency fluctuation when changing the output of renewable energy in summer and winter in a step-like manner is shown in Figure 4. In $10 \mathrm{~s}$ after the beginning of the analysis, the solar radiation amount was a step-change from $1 \mathrm{~kW} / \mathrm{m}^{2}$ to $0 \mathrm{~kW} / \mathrm{m}^{2}$ and the wind speed was a step-change from the rated wind speed of wind power generation to the cut-out wind speed. In summer, when the amount of renewable energy introduced is $25 \%$ of the maximum load, the maximum frequency fluctuation of the transmission network is $49.7 \mathrm{~Hz}$. In the case of winter, when the introduced amount of renewable energy is $25 \%$ of the maximum load, the maximum frequency variation was 49.7Hz. Therefore, the limit for introducing renewable energy at SBMG is $25 \mathrm{~kW}$ for solar power and $25 \mathrm{~kW}$ for wind power. In addition, the percentage of renewable energy in summer and mid-term is $25 \%$ of the load, and the percentage of renewable energy in winter is $12.5 \%$ of the load.

Figure 4. Transmission network frequency fluctuation in summer and winter. 


\section{Conclusion}

In this paper, we analyzed the frequency variation in SBMG. From the results, the following conclusions were obtained.

1) Among the sources of introduced renewable energy, the frequency fluctuation can be controlled the most by making Photovoltaics generation and wind power generation equal.

2) Based on the power quality of the grid, the introduction limit of renewable energy in summer is about $25 \%$ of the maximum load and $12.5 \%$ in winter.

\section{References}

1. S.Masakawa, " Diesel engine active at Syowa Station-For comfortable and safe activities in Antarctica,"

2. National Institute of Polar Research "http://polaris.nipr.ac.jp/ academy/science/shirase/ index.html "

3. S. Nishikawa, H. Abiko, J. Kurihara, K. Ishizawa and N. Endo, " Fundamental study for introduction of renewable energy into Showa Base," IEEJ Transactions on Power and Energy, vol. 9, pp. 778-785, Sep. 2011

4. S. Iwamoto, "Issues and future prospects of Japanese power systems"

5. H. Kubota, "A record of stay in Antarctica"

6. Y. Zhu, K. Tomsovic,"Development of models for analyzing the load-following performance of microturbines and fuel cells" 